\title{
Weight Loss Attempts among Kuwaiti Adults Attending the Central Medical Nutrition Clinic
}

\author{
Nawal Al-Qaoud Prasanna Prakash Susan Jacob \\ Ministry of Health, Food and Nutrition Administration, Kuwait
}

\section{Key Words}

Obesity $\cdot$ Weight loss attempts $\cdot$ Weight loss perception

\begin{abstract}
Objectives: To investigate the reasons for attempting to lose weight and identify weight loss perception and characteristics. Methods: A cross-sectional survey of a sample of 526 Kuwaiti adults was carried out at the Central Medical Nutrition Clinic, Kuwait, from August to December 2003. Heights and weights were measured and body mass index (BMI) was calculated and classified according to WHO grades of obesity. A structured questionnaire used for collecting data was analyzed using SPSS version 12.0. Results: Of the 526 subjects, the most commonly cited reasons for attempting to lose weight were to avoid health problems ( $n=248,47.1 \%)$ followed by improving personal appearance $(n=141,26.8 \%)$. The weight loss perceptions of $263(50 \%)$ of the subjects were within the accepted range ( $2-5 \mathrm{~kg} /$ month); 321 (61.0\%) had previously attempted to lose weight, among them 147 (45.8\%) followed the advice of doctors and dieticians. The major reason mentioned for stopping the previous dietary regime was inability to resist sweets and traditional foods $(n=99,31.0 \%)$ followed by dissatisfaction with the dietary outcome ( $n=79,24.8 \%)$. Conclusion: The study confirms an awareness of the health risks of obesity, but an inability among the dieters to maintain a weight loss program. Hence,
\end{abstract}

behavioral management techniques may be necessary to develop nutritional education approaches and effective weight management strategies.

Copyright $\odot 2007$ S. Karger AG, Basel

\section{Introduction}

Obesity may be described as the 'New World Syndrome'. Its prevalence is on continuous rise in all age groups in many developed and wealthy developing countries. Statistical data reveal that the problem of obesity has increased from 12 to 20 and 16 to $25 \%$ in men and women, respectively, over the last 10 years [1].

Obesity has been on the increase among people of the Arabian Gulf countries, reaching epidemic proportions, and remains a major nutritional public health problem [2, 3]. According to previous studies, obesity in Kuwait is increasing and is the highest among the Gulf countries, even higher than in some European countries [4-7]. It is known that obesity is a risk factor for a variety of diseases, including diabetes, hypertension, some forms of cancer, cardiovascular and kidney diseases and gall bladder disorders, which are also prevalent in Kuwait [8]. The widespread concern about being overweight has increased the prevalence of weight change attempts in populations [9]. Attempting weight loss is a common behavior regard-

\section{KARGER}

Fax +4161306 1234

E-Mail karger@karger.ch

www.karger.com
(C) 2007 S. Karger AG, Basel

1011-7571/07/0164-0291\$23.50/0

Accessible online at:

www.karger.com/mpp 
less of age, gender or ethnicity [10]. For many overweight persons, achieving and maintaining a healthy weight is a lifelong challenge.

Studies have shown that there is a general consensus that the best treatment regimen is a combination of energy intake reduction and regular exercise [11]. The benefits of physical activity, diet and weight control, which can be influenced by many personal, psychosocial, and environmental factors that have been identified as barriers in following a healthy diet and exercise regimen, are well described in the literature [11].

Although weight control measures are in the public interest, little national data on weight loss practices and specific aspects of this behavior in the general population are available in Kuwait. Therefore, the present study was conducted to investigate the reasons and identify weight loss perceptions and characteristics of those attempting to lose weight.

\section{Subjects and Methods}

\section{Subjects}

A cross-sectional survey method was followed for the study. Kuwaiti adults formed the study population, and the study was conducted at the Central Medical Nutrition Clinic, a government clinic under the Ministry of Health. This clinic receives patients from the entire state of Kuwait, as it is the main Medical Nutrition Clinic. It provides services to the patients who require diet therapy or counseling for diet modification. Generally, anthropometric measurements and complete blood count are obtained for all registered patients. The study was explained to the patients and verbal consent to participate was obtained. Patients were selected from the outpatient clinic from August to December 2003, proportionate to the total number of overweight and obese served by the center during the entire year. Of the 616 patients recruited for the study, 90 were excluded because of age ( $<18$ years old) and a BMI of $<25$. Thus, the analytical sample consisted of 526 adults (423 females and 103 males) who visited the outpatient clinic during the study period. The number of samples for females was greater than for males, as generally more females attend the clinic.

\section{Survey Tool}

The survey tool consisted of actual height and weight measurements and a questionnaire. Height and weight were measured without shoes; height to the nearest $0.1 \mathrm{~cm}$ and weight to the nearest $0.1 \mathrm{~kg}$ using an electronic SECA scale, model 220. All measurements were taken during working hours ( $8-12$ noon) to avoid variation. Body mass index (BMI), weight in $\mathrm{kg} /(\text { height in } \mathrm{m})^{2}$, was calculated and classified as per WHO classification, i.e. overweight $\geq 25$, obese $\geq 30$ and morbidly obese $\geq 40$.

A modified version of a structured questionnaire, pretested for reliability and validity was used for demographic information: age, gender, education, occupation, marital status, reasons for attempting weight loss, weight loss perceptions and characteristics
Table 1. Demographic characteristics

\begin{tabular}{|c|c|c|}
\hline & \multicolumn{2}{|c|}{ Patients $(n=526)$} \\
\hline & $\mathrm{n}$ & $\%$ \\
\hline \multicolumn{3}{|l|}{ Age $($ mean age $=36.0$ years $)$} \\
\hline$<30$ years & 174 & 33.0 \\
\hline 30-39 years & 165 & 31.4 \\
\hline$\geq 40$ years & 187 & 35.6 \\
\hline \multicolumn{3}{|l|}{ Gender } \\
\hline Male & 103 & 19.6 \\
\hline Female & 423 & 80.4 \\
\hline \multicolumn{3}{|l|}{ Marital status } \\
\hline Unmarried & 126 & 24.0 \\
\hline Married & 400 & 76.0 \\
\hline \multicolumn{3}{|l|}{ Education } \\
\hline Up to secondary & 226 & 43.0 \\
\hline Diploma & 146 & 27.8 \\
\hline Graduation and above & 154 & 29.3 \\
\hline \multicolumn{3}{|l|}{ Occupation } \\
\hline Employed & 281 & 53.4 \\
\hline Unemployed & 245 & 46.6 \\
\hline \multicolumn{3}{|l|}{ BMI (mean BMI = 34.2) } \\
\hline$\geq 25$ (overweight) & 145 & 27.6 \\
\hline$\geq 30$ (obese) & 304 & 57.8 \\
\hline$\geq 40$ (morbidly obese) & 77 & 14.6 \\
\hline
\end{tabular}

of weight loss attempts. The subjects themselves completed the questionnaire with assistance by the principal investigator and other trained technicians to clarify doubts and difficulties.

\section{Data Analysis}

The collected data were grouped and analyzed using Statistical Package for Social Sciences, v12.0. In addition to descriptive statistics, the $\chi^{2}$ test was used to assess the association between categorical variables and trend. Fisher's exact test, Kruskal-Wallis test and Mann-Whitney test were also used for analysis.

\section{Results}

The demographic attributes of the subjects are summarized in table 1 . Of the 526 subjects, $423(80.4 \%)$ were females; 400 (76.0\%) were married and 77 (14.6\%) morbidly obese. Almost equal percentages were from three age groups studied.

\section{Reasons for Attempting to Lose Weight}

The most commonly cited reasons for attempting to lose weight (table 2) were to avoid health problems ( $\mathrm{n}=$ $248,47.1 \%)$ and improve personal appearance $(\mathrm{n}=141$, 26.8\%). No significant gender-specific differences were found in reasons to attempt to lose weight. Significant 
Table 2. Association of reasons for attempting to lose weight and demographic variables

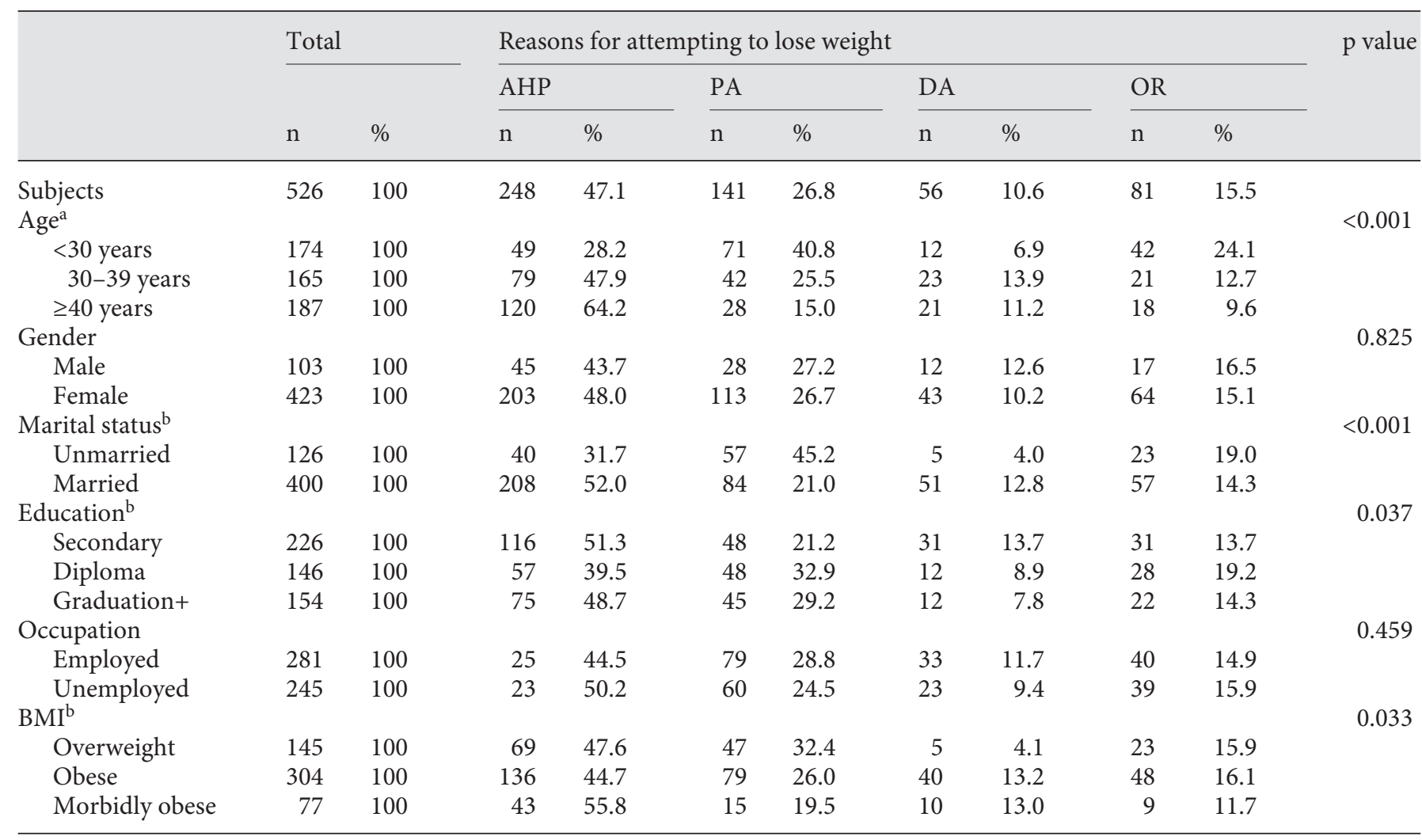

AHP = Avoid health problem; PA = personal appearance; DA = doctor's advice; $\mathrm{OR}=$ other reasons (family/social pressure; avoid insults; start a new job; about to marry; planning for pregnancy; a particular occasion; set an example of healthy weight for my family).

${ }^{\mathrm{a}} \mathrm{p}$ value based on $\chi^{2}$ for trend; ${ }^{\mathrm{b}} \mathrm{p}$ value based on $\chi^{2}$ test.

differences in reasons for attempting to lose weight were found between the different categories of marital status $(\mathrm{p}<0.001)$, education $(\mathrm{p}<0.04)$, and BMI $(\mathrm{p}<0.03)$. Differences were found between subjects who attempted to lose weight to avoid health problems: 208 (52.0\%) of married subjects compared to 40 (31.7\%) of unmarried subjects, $116(51.3 \%)$ of subjects with a secondary education compared to 75 (48.7\%) of subjects with a university degree and above. Forty-seven (32.4\%) of overweight subjects compared to 15 (19.5\%) of morbidly obese subjects attempted to lose weight for personal appearance. Fewer participants, 5 (4.1\%) of overweight subjects compared to $40(13.2 \%)$ of obese subjects and $10(13.0 \%)$ of morbidly obese subjects, attempted to lose weight according to doctor's advice.

Differences in trend were significantly associated with different age groups $(\mathrm{p}<0.001)$, where $120(64.2 \%)$ of the $\geq 40$-year-olds compared with $49(28.2 \%)$ of the $<30$ - year-olds were attempting to lose weight to avoid health problems.

\section{Weight Loss Perceptions}

The perception of 263/526 (50\%) subjects was within the accepted range of weight reduction of $2-5 \mathrm{~kg} / \mathrm{month}$ (table 3$)$. Highly significant differences $(\mathrm{p}=0.004)$ in weight loss perceptions were noted among different age groups; while 26 (13.9\%) of $\geq 40$-year-olds perceived $<2 \mathrm{~kg} / \mathrm{month}$ as normal weight reduction, the same perception was shared by only $10(5.7 \%)$ of $<30$-year-olds and $7(3.6 \%)$ of 30 - to 39 -year-olds. There was no association between the other demographic variables and perception of weight loss.

\section{Characteristics of Weight Loss Attempts}

The characteristics of weight loss attempts and association of demographic variables are given in table 4 . Of 
Table 3. Association of perception of weight loss per month and demographic variables

\begin{tabular}{|c|c|c|c|c|c|c|c|c|c|}
\hline & \multirow{2}{*}{\multicolumn{2}{|c|}{ Total }} & \multicolumn{6}{|c|}{ Perception of weight loss per month } & \multirow[t]{3}{*}{$\mathrm{p}$ value } \\
\hline & & & \multicolumn{2}{|c|}{$<2 \mathrm{~kg}$} & \multicolumn{2}{|c|}{$2-5 \mathrm{~kg}$} & \multicolumn{2}{|c|}{$\geq 5 \mathrm{~kg}$} & \\
\hline & $\mathrm{n}$ & $\%$ & $\mathrm{n}$ & $\%$ & $\mathrm{n}$ & $\%$ & $\mathrm{n}$ & $\%$ & \\
\hline Subjects & 526 & 100 & 42 & 8.0 & 263 & 50.0 & 221 & 42.0 & \\
\hline $\operatorname{Age}^{\mathrm{a}}$ & & & & & & & & & 0.004 \\
\hline$<30$ years & 174 & 100 & 10 & 5.7 & 90 & 51.7 & 74 & 42.5 & \\
\hline 30-39 years & 165 & 100 & 7 & 3.6 & 82 & 49.7 & 77 & 46.7 & \\
\hline$\geq 40$ years & 187 & 100 & 26 & 13.9 & 91 & 48.7 & 70 & 37.4 & \\
\hline Gender & & & & & & & & & 0.071 \\
\hline Male & 103 & 100 & 11 & 11.7 & 41 & 40.8 & 50 & 47.6 & \\
\hline Female & 423 & 100 & 30 & 7.1 & 221 & 52.2 & 172 & 40.7 & \\
\hline Marital status & & & & & & & & & 0.706 \\
\hline Unmarried & 126 & 100 & 9 & 7.1 & 67 & 53.2 & 51 & 39.7 & \\
\hline Married & 400 & 100 & 32 & 8.3 & 196 & 49.0 & 171 & 42.8 & \\
\hline Education & & & & & & & & & 0.343 \\
\hline Secondary & 226 & 100 & 17 & 10.6 & 108 & 47.8 & 94 & 41.6 & \\
\hline Diploma & 146 & 100 & 22 & 6.2 & 72 & 49.3 & 65 & 44.5 & \\
\hline Graduation+ & 154 & 100 & 2 & 5.8 & 83 & 53.9 & 62 & 40.3 & \\
\hline Occupation & & & & & & & & & 0.734 \\
\hline Employed & 281 & 100 & 20 & 7.1 & 142 & 50.5 & 119 & 42.3 & \\
\hline Unemployed & 245 & 100 & 22 & 9.0 & 121 & 9.4 & 102 & 41.6 & \\
\hline BMI & & & & & & & & & 0.088 \\
\hline Overweight & 145 & 100 & 17 & 11.7 & 73 & 49.7 & 56 & 38.6 & \\
\hline Obese & 304 & 100 & 22 & 7.6 & 156 & 51.3 & 125 & 41.1 & \\
\hline Morbidly obese & 77 & 100 & 2 & 2.6 & 35 & 45.5 & 40 & 51.9 & \\
\hline
\end{tabular}

the 526 subjects, $321(61.0 \%)$ had made previous attempts to lose weight. Significant differences in trends were noted for gender $(\mathrm{p}<0.001)$ and marital status $(\mathrm{p}<0.05)$, where $275(65.0 \%)$ of females compared to $46(44.7 \%)$ of males, 254 (63.5\%) of married compared to 67 (53.2\%) of unmarried subjects had made previous weight loss attempts.

The source of information for previous attempts at weight loss is given in table 5 . Of the 321 subjects that had attempted weight loss previously, 147 (45.8\%) followed the advice of doctors and dieticians. Significant differences $(\mathrm{p}=0.003)$ were noted among the different age groups, where 67 (56.3\%) of $\geq 40$-year-olds followed diets prescribed by doctors and dietitians. On the other hand, the majority ( $\mathrm{n}=61,63.5 \%)$ of $<30$-year-olds followed diets by other means such as magazines, internet, friends, etc. No significant association was found for gender, marital status, education and BMI. But significant differences in trend $(\mathrm{p}=0.043)$ were noted between the person who prescribed the diet and the occupation of the participants: 77 (52.0\%) of the unemployed patients followed the diet prescribed by the doctors and dieticians compared to $70(40.5 \%)$ of the employed patients.

The association between demographic variables and reasons for stopping a previous diet is given in table 6. Of the 321 subjects who had attempted to lose weight previously, the major reasons for quitting included inability to resist sweets and traditional food $(\mathrm{n}=99,31 \%)$ and dissatisfaction with the dietary outcome $(\mathrm{n}=79 ; 24.8 \%)$. Table 6 shows the significant differences $(\mathrm{p}<0.05)$ in the association of reasons for stopping the previous diet regime with age and marital status, where $44(37.6 \%)$ of $\geq 40$-year-olds compared to $24(25.0 \%)$ of $<30$-year-olds were unable to resist sweets and traditional foods; 34 (35.4\%) of $<30$-year-olds compared to $18(15.4 \%)$ of $\geq 40$ year-olds were not satisfied with the dietary outcome. The differences in reasons among subjects with regard to marital status show that $83(32.9 \%)$ of married compared to $16(23.9 \%)$ of unmarried were unable to resist sweets and traditional foods; 58 (23.0\%) of married compared to $21(31.3 \%)$ of unmarried were not satisfied with the dietary outcome; 29 (11.5\%) of married compared to 15 
Table 4. Association of demographic variables and previous weight loss attempts

\begin{tabular}{|c|c|c|c|c|c|c|c|}
\hline & \multirow{2}{*}{\multicolumn{2}{|c|}{ Total }} & \multicolumn{4}{|c|}{ Previous attempts } & \multirow[t]{3}{*}{$\mathrm{p}$ value } \\
\hline & & & \multicolumn{2}{|l|}{ yes } & \multicolumn{2}{|l|}{ no } & \\
\hline & $\mathrm{n}$ & $\%$ & $\mathrm{n}$ & $\%$ & $\mathrm{n}$ & $\%$ & \\
\hline Subjects & 526 & 100 & 321 & 61.0 & 205 & 39.0 & \\
\hline Age & & & & & & & 0.153 \\
\hline$<30$ years & 174 & 100 & 96 & 55.2 & 78 & 44.8 & \\
\hline 30-39 years & 165 & 100 & 106 & 64.2 & 59 & 35.8 & \\
\hline$\geq 40$ years & 187 & 100 & 119 & 63.6 & 68 & 36.4 & \\
\hline Gender ${ }^{\mathrm{a}}$ & & & & & & & $<0.001$ \\
\hline Male & 103 & 100 & 46 & 44.7 & 57 & 55.3 & \\
\hline Female & 423 & 100 & 275 & 65.0 & 148 & 35.0 & \\
\hline Marital status $^{\mathrm{a}}$ & & & & & & & 0.046 \\
\hline Unmarried & 126 & 100 & 67 & 53.2 & 59 & 46.8 & \\
\hline Married & 400 & 100 & 254 & 63.5 & 146 & 36.5 & \\
\hline Education & & & & & & & 0.732 \\
\hline Secondary & 226 & 100 & 135 & 59.7 & 91 & 40.3 & \\
\hline Diploma & 146 & 100 & 93 & 63.7 & 53 & 36.3 & \\
\hline Graduation+ & 154 & 100 & 93 & 60.4 & 61 & 39.6 & \\
\hline Occupation & & & & & & & 0.789 \\
\hline Employed & 281 & 100 & 173 & 61.6 & 108 & 38.4 & \\
\hline Unemployed & 245 & 100 & 148 & 60.4 & 97 & 39.6 & \\
\hline BMI & & & & & & & 0.819 \\
\hline Overweight & 145 & 100 & 86 & 59.3 & 59 & 40.7 & \\
\hline Obese & 304 & 100 & 189 & 62.2 & 115 & 37.8 & \\
\hline Morbidly obese & 77 & 100 & 46 & 59.7 & 31 & 40.3 & \\
\hline
\end{tabular}

(22.4\%) of unmarried stopped the diet because it lacked variety; $29(11.5 \%)$ of married compared to $4(6.0 \%)$ of unmarried stopped the diet because of cost.

The significant association of reasons for stopping the diet with regard to trend $(\mathrm{p}=0.015)$ among subjects with different levels of education shows that 28 (30.4\%) of subjects with a university degree and above compared to 25 (18.7\%) of those with a secondary education were not satisfied with the dietary outcome, while 20 (14.9\%) of subjects with a secondary education compared to $5(5.4 \%)$ of those with a university degree were not satisfied with the cost of the diet.

\section{Discussion}

The study reflects gender differences among the Kuwaiti population, where the prevalence rates of obesity and weight loss attempts are higher among females. More Kuwaiti women than men showed a greater awareness, desire, and willingness to lose weight, as they outnum- bered men in visiting the obesity clinic. This result is similar to previous reports $[12,13]$. In addition, the study confirms that overweight and obese Kuwaiti adults are concerned about their weight; therefore, weight modification efforts are also common among them. Moreover, they are aware of the facilities provided by the Central Medical Nutrition Clinic and consider it in their weight loss attempts.

Our study also confirms that weight loss attempts are found to be strongly associated with BMI status. Fortunately, the most commonly mentioned reason to attempt weight loss was to avoid health problems related to obesity, followed by increasing attractiveness, which is in accordance with the findings of Green and Cameron [13].

In our study, there was no gender difference in reasons for attempting to lose weight. As individuals get older, they are at more risk of developing chronic diseases, and the risk increases when predisposing factors such as heredity coexist. Hence, it is natural for older individuals with a higher BMI to be more conscious of health and attempt to lose weight to avoid health problems. 
Table 5. Association of demographic variables and source of diet information for weight loss attempts

\begin{tabular}{|c|c|c|c|c|c|c|c|}
\hline & \multirow{2}{*}{\multicolumn{2}{|c|}{ Total }} & \multicolumn{4}{|c|}{ Source of diet information } & \multirow[t]{3}{*}{$\mathrm{p}$ value } \\
\hline & & & \multicolumn{2}{|c|}{ DOC } & \multicolumn{2}{|l|}{ OR } & \\
\hline & $\mathrm{n}$ & $\%$ & $\mathrm{n}$ & $\%$ & $\mathrm{n}$ & $\%$ & \\
\hline Subjects & 321 & 100 & 147 & 45.8 & 174 & 54.2 & \\
\hline $\operatorname{Age}^{a}$ & & & & & & & 0.003 \\
\hline$<30$ years & 96 & 100 & 35 & 36.5 & 61 & 63.5 & \\
\hline 30-39 years & 106 & 100 & 45 & 42.5 & 61 & 57.5 & \\
\hline$\geq 40$ years & 119 & 100 & 67 & 56.3 & 52 & 43.7 & \\
\hline Gender & & & & & & & 0.527 \\
\hline Male & 46 & 100 & 19 & 41.3 & 27 & 58.7 & \\
\hline Female & 275 & 100 & 128 & 46.5 & 147 & 53.5 & \\
\hline Marital status & & & & & & & 0.074 \\
\hline Unmarried & 67 & 100 & 24 & 35.8 & 43 & 64.2 & \\
\hline Married & 254 & 100 & 123 & 48.4 & 131 & 51.6 & \\
\hline Education & & & & & & & 0.064 \\
\hline Secondary & 135 & 100 & 68 & 50.4 & 67 & 49.6 & \\
\hline Diploma & 93 & 100 & 44 & 47.3 & 49 & 52.7 & \\
\hline Graduation+ & 93 & 100 & 35 & 37.6 & 58 & 62.4 & \\
\hline Occupation $^{\mathrm{b}}$ & & & & & & & 0.043 \\
\hline Employed & 173 & 100 & 70 & 40.5 & 103 & 59.5 & \\
\hline Unemployed & 148 & 100 & 77 & 52.0 & 71 & 48.0 & \\
\hline BMI & & & & & & & 0.077 \\
\hline Overweight & 86 & 100 & 39 & 45.3 & 47 & 54.7 & \\
\hline Obese & 189 & 100 & 80 & 42.3 & 109 & 57.7 & \\
\hline Morbidly obese & 46 & 100 & 28 & 60.9 & 18 & 39.1 & \\
\hline
\end{tabular}

Gradual losses of $0.500-1 \mathrm{~kg} /$ week are the limit for individuals who want to lose weight. Rapid weight loss may involve the risk of excessive loss of lean body mass, nutrient deficiencies, metabolic abnormalities, fatigue, and other adverse effects. Moreover, weight loss exceeding $0.500-1 \mathrm{~kg} /$ week is rarely sustainable in outpatient treatment settings [10]. The perception of $50 \%$ of $\mathrm{Ku}-$ waiti adults regarding the range of weight reduction per month is in accordance with recommended weight loss. This reflects a high degree of awareness of health hazards associated with rapid weight loss methods among Kuwaitis.

Individual approaches to weight loss attempts may be characterized by their duration and recurrent nature. The characteristics of Kuwaiti adults identified by this study are consistent with other studies $[13,14,15]$, indicating that weight loss attempts are more common among females and married people. Another important characteristic noted among Kuwaiti adults is that they consult dieticians and doctors in their weight loss attempts. How- ever, Cade and Connell [16] found doctors to be less effective than the media or the family in persuading the overweight patient to lose weight. A trend noticed among Kuwaiti adults in the present study was that married people followed the diet for a longer period and lost more weight in their attempts, which indicates the social and familial support.

The major reasons for stopping the previous dietary regime were inability to resist sweets and traditional foods, as previously reported by Jasem and Al Hamad [14] and Musaiger [17]. Education was also a significant predictor of weight loss attempts: the more educated were more dissatisfied with weight loss outcomes, a finding similar to the one of Alan et al. [18] but not of Levy et al. [15], who suggested that additional knowledge of nutrition would not help the obese in controlling their obesity. The factors felt to be important were exercise and selfmotivation [19].

This study indicates that Kuwaitis are health conscious and may be able to obtain nutrition information 
Table 6. Association of demographic variables and reasons for stopping previous diet

\begin{tabular}{|c|c|c|c|c|c|c|c|c|c|c|c|c|c|c|c|}
\hline & \multicolumn{2}{|c|}{ Total } & \multicolumn{12}{|c|}{ Reasons for stopping previous diet } & \multirow{2}{*}{$\begin{array}{l}\mathrm{p} \\
\text { value }\end{array}$} \\
\hline & $\mathrm{n}$ & $\%$ & $\mathrm{n}$ & $\%$ & $\mathrm{n}$ & $\%$ & $\mathrm{n}$ & $\%$ & $\mathrm{n}$ & $\%$ & $\mathrm{n}$ & $\%$ & $\mathrm{n}$ & $\%$ & \\
\hline Subjects & 321 & 100 & 99 & 31.0 & 79 & 24.8 & 44 & 13.8 & 33 & 10.3 & 24 & 7.5 & 40 & 12.5 & \\
\hline Age $^{a}$ & & & & & & & & & & & & & & & 0.042 \\
\hline$<30$ years & 96 & 100 & 24 & 25.0 & 34 & 35.4 & 16 & 16.7 & 5 & 5.2 & 5 & 5.2 & 12 & 12.5 & \\
\hline Gender & & & & & & & & & & & & & & & 0.267 \\
\hline Male & 46 & 100 & 9 & 19.6 & 14 & 30.4 & 8 & 17.4 & 3 & 6.5 & 6 & 13.0 & 6 & 13.0 & \\
\hline Female & 275 & 100 & 90 & 33.0 & 65 & 23.8 & 36 & 13.2 & 30 & 11.0 & 18 & 6.6 & 34 & 12.5 & \\
\hline Marital status ${ }^{\mathrm{a}}$ & & & & & & & & & & & & & & & 0.045 \\
\hline Unmarried & 67 & 100 & 16 & 23.9 & 21 & 31.3 & 15 & 22.4 & 4 & 6.0 & 2 & 3.0 & 9 & 13.4 & \\
\hline Graduation+ & 93 & 100 & 32 & 34.8 & 28 & 30.4 & 11 & 12.0 & 5 & 5.4 & 7 & 7.6 & 9 & 9.8 & \\
\hline Occupation & & & & & & & & & & & & & & & 0.444 \\
\hline Employed & 173 & 100 & 57 & 32.9 & 45 & 26.0 & 23 & 13.3 & 17 & 9.8 & 15 & 8.7 & 16 & 9.2 & \\
\hline Unemployed & 148 & 100 & 42 & 28.8 & 34 & 23.3 & 21 & 14.4 & 16 & 11.0 & 9 & 6.2 & 24 & 16.4 & \\
\hline \multicolumn{16}{|l|}{ BMI } \\
\hline Overweight & 86 & 100 & 29 & 33.7 & 18 & 20.9 & 10 & 11.6 & 8 & 9.3 & 11 & 12.8 & 10 & 11.6 & 0.250 \\
\hline Obese & 189 & 100 & 54 & 28.9 & 55 & 29.4 & 26 & 13.9 & 21 & 11.2 & 9 & 4.8 & 22 & 11.8 & \\
\hline Morbidly obese & 46 & 100 & 16 & 34.8 & 6 & 13.0 & 8 & 17.4 & 4 & 8.7 & 4 & 8.7 & 8 & 17.4 & \\
\hline
\end{tabular}

through the media and technology. However, many researchers in behavioral psychology and sociology have demonstrated that knowledge alone is not enough to change behavior [14]. Hence behavioral management techniques may also be considered for nutrition educational approaches and the development of effective weight management strategies. The challenge is therefore to develop culturally appropriate interventions aimed at promoting healthy weight control behaviors.

\section{Conclusion}

The study confirms the existence of awareness, health consciousness and social support to lose weight, but found a lack of self-control, commitment and focus among the dieters. Hence, behavioral management techniques may also be considered for nutritional education approaches and the development of effective weight management strategies.

\section{Acknowledgements}

We thank all the patients who participated in the study and acknowledge our gratitude to the data collectors of the outpatient unit of Central Medical Nutrition Clinic, Ministry of Health, Kuwait.

References $\nabla_{1}$ Flegal KM, Caroll MD, Kuczmarski RJ: Overweight and obesity in the United States, prevalence and trends. 1960-1994. Int J Obes Relat Metab Disord 1998;22:39-47.

$\checkmark 2$ Musaiger AO: Nutritional disorders associated with obesity and its prevalence in Baharin. Fam Pract 1990;7:9-13.

3 Al-Isa AN: Temporal changes in BMI and obesity among Kuwaiti men. Ann Nutr Metab 1997;41:307-314.

4 Al-Moussa: Nutrition-related chronic diseases in Kuwait; in Musaiger AO (ed): DietRelated Non-Communicable Diseases in Arab Countries of Gulf. Cairo, FAO/RNEA, 1996. 
5 Kuwait Nutrition Surveillance Report 2005. Administration of Food and Nutrition, Ministry of Health, Kuwait.

-6 Al Awadi F, Amine EK: Overweight and obesity in Kuwait. J R Soc Health 1999;109:175177.

7 Bellisle F, Monneuse MO, Steptoe A, Wardle $\mathrm{J}$ : Weight concerns and eating patterns: a survey of university students in Europe. Int J Obes Relat Metab Disord 1995;19:723730

8 Gingras LR: Body image dissatisfaction, a framework of development and recommendations for dietitions. Can J Diet Pract Res 1998;59:132-137.

-9 Teixeira PJ, Palmeira AL, Branco TL, Martins SS, Minderico CS, Barata JT, Silva AM, Sardinha MB: Who will lose weight? A reexamination of predictors of weight loss in women. Int J Behav Nutr Phys Act 2004;1: $12-18$.
10 Olson CL, Schumaker HD, Yawn BP: Overweight women delay medical care. Arch Fam Med 1994;10:888-892.

11 George LB, Beatrice SK: Obesity Pathophysiology Psychology and Treatment. New York, Chapman \& Hall, 1994, pp 22-23.

12 Timperio A, Cameron-Smith D, Burns C, Crawford D: The public's response to obesity epidemic in Australia: weight concerns and weight control practices of men and women. Public Health Nutr 2000;4:417-424.

13 Green KL, Cameron R: Weight dissatisfaction and weight loss attempts among Canadian adults. Canadian Heart Health Surveys Research Group. CMAJ 1997;157: $17-25$.
14 Jasem L, Al Hamad NM : Lack of self control, social support, and taste for healthy food are barriers to following a healthy diet regimen in Kuwait. Unpublished report, 2001

15 Levy BT, Williamson PS: Patient perceptions and weight loss of obese adults. J Fam Pract 1988;3:285-290.

16 Cade JO, Connell S: Management of weight problems and obesity; knowledge, attitudes and current practice of general practitioners. Br J Gen Pract 1991;345:147-150.

17 Musaiger A: The study of food habits in urban and rural areas in Bahrain; masters thesis, Alexandria, 1997.

18 Heaton AW, Levy AS: Information sources of U.S. adults trying to lose weight. J Nutr Edu 1995;27:182-190.

19 Martin PD, Rhode PC, Howe JT, Brantley PJ: Primary care weight management counseling. Physician and patient perspectives. J La State Med Soc 2003;155:52-56. 